\title{
The Concept "Modesty" in the Context of British, American and Armenian Cultural Identity
}

\author{
Gayane Yeghiazaryan \\ Yerevan State Linguistic University \\ "Be modest! It is the kind of pride least likely to offend." \\ (Jules Renard, 1864-1910)
}

$\mathrm{T}$ he question of how we know ourselves and others is of fundamental interest for successful cross-cultural communication. We suggest that identity theory may assist in this regard, and we focus on the analysis of cultural identity, restricting our attention to a particular aspect - the concept of modesty, emphasizing its role in creating a sense of self and self-worth. The contrastive analysis of the concept modesty in English and Armenian demonstrates the subtle but crucial differences in the ways socio-cultural relations shape cultural identities.

Linguo-cultural identity as applied to concept description is a comparatively new and a very interesting topic. It is established as the methodological basis for the description of the common cultural knowledge of a speech community, which serves as the basis for the formation of stereotypical perceptions, including linguo-cultural stereotypes. The term cultural identity, after a comprehensive review of philosophical and psychological literature, was defined as "an individual's realization of his or her place in the spectrum of cultures and purposeful behavior directed on his or her enrollment and acceptance into a particular group, as well as certain characteristic features of a particular group that automatically assign an individual's group membership" (Sysoyev 2001b:37-38). Thus, the concept of cultural identity can be employed as a reference to the collective self-awareness that a given group embodies and reflects. Used in its collective sense, the concept of cultural identity includes typologies of cultural behavior, incorporates the shared premises, values, definitions, and beliefs and the day-to-day, largely unconscious, patterning of activities.

Cultural identity is a very influential factor in behaviour and attitudes, in what one can or cannot do, or even in what one can or cannot imagine doing. All cultures seek for moral and ethical values and ways to preserve these values. How an individual raises these questions and searches for ultimate answers is a function of the psycho-philosophical patterning of cultural identity (Adler 1976:362-378).

The "links" between the cultural values and cultural identity are reciprocal. On the one hand, cultural values make explicit the nation's hidden constructs through its attitudes towards the concepts of fate and destiny, power and hierarchy, modesty, and other facets. On the other hand, these values shape and determine this or that cultural identity and dictate the rules and behavior codes for the very nation. In fact, cultural values structure our mental frames, determine our patterns of thinking and can affect social interactions which in their turn are deeply embedded in language. Language expresses the patterns and structures of culture, and conse- 
quently influences human thinking, thus determining cultural identity, which is expressed by different concepts. Linguo-cultural concepts can be objectively identified and described through the analysis of dictionary definitions, value-labeled universal statements and the individual content of concepts considering their etymology.

One of the social and ethical regulators is the concept of modesty, which is a conscious desire and ability of man not to put himself/herself in the spotlight, while maintaining selfesteem. The ethical concept modesty in British, American ${ }^{1}$ and Armenian linguo-cultures, along with many similarities, manifests some differences peculiar to these very cultures, thus determining and shaping different cultural identities. The relevance of the study is due to the fact that the concept of modesty reflects the important features of the relationship of man to reality, and thus, the understanding of its specificities will ease cross-cultural communication. The following hypothesis is put forward: 1) the concept of modesty is an ethical value, the contents of which can be represented in the form of certain norms of behaviour and can define a dominant behaviour and speech norms in the compared linguocultures, 2) this concept is characterized by specific conceptual, and value attributes in British, American and Armenian linguo-cultures.

Modesty has been used as a communication pattern, a sociological concept related to self-presentation and self-esteem, and a religious virtue. Attention to the concept is far more prevalent in references from the early part of $19^{\text {th }}$ century, and concepts of modesty are determined by cultural as well as historical factors. Etymologically linked to the Latin modestus, "keeping within measure", this term originally signified moderation, as in Cicero's "golden mean of living". Gradually, modesty took on the gendered connotation of a sexual virtue particularly important for women. ${ }^{2}$ Since the 1530 s it has acquired the meaning of "having self-control, freedom from exaggeration". Since the 1550 s the meaning of "having a moderate opinion of oneself" came into use, and since the 1560s the meaning of "womanly propriety" was added (Laver 1969).

In Armenian it has the following origin: zuukuun - QGn. Hamoistri - «qtiunhG qun-

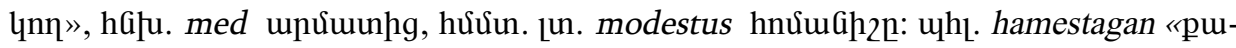
цupua qGuugnn hnqhGitinn»:

The English Psychology Dictionary defines modesty (also called demureness or reticence) as "the name for a number of norms of behaviour a society expects form the individual people that make up this society".

According to the American Heritage Dictionary, modesty consists in observing the conventional proprieties in speech, dress, and behaviour.

The Armenian Psychological Dictionary defines modesty as a trait of character which presupposes that a person does not boast of his/her achievements, does not overestimate his/her capabilities, and respects others.

Modesty, then, denotes a moderate self-view - seeing oneself as intermediate, rather than as very positive or very negative, on key personal attributes such as personality traits, abilities and skills, physical appearance, and social behaviour. A moderate self-view may be entertained privately or expressed publicly. Probably the apprehension of modesty is given substantially the same form by experience irrespective of culture. Yet, there are subtle, but, crucial differences in English and Armenian concerning the definition of the 
word modesty. It must be emphasized that some underlying abstractions are different and more justified pragmatically and experientially and they will vary somewhat within these linguo-cultures, because they are closely linked with the cultural identifications.

Roget's Thesaurus defines modesty as: 1. Lack of vanity or self importance: humbleness, humility, lowliness, meekness. 2. Reserve in speech, behavior, or dress: demureness, diffidence, reticement, self-effacement. 3. The condition of being chaste: chasity, decency, innocence, purity, virginity, virtue, virtuousness. 4. Lack of ostentation or pretension: plainness, simpleness, simplicity, unassumingness, unpretentiousness.

In Armenian dictionaries the following meanings of modesty are stated: Zuudhuynn-

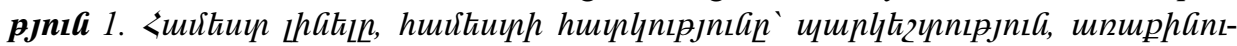

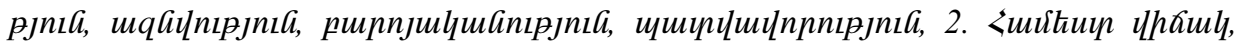

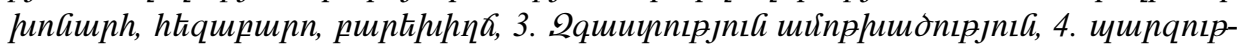

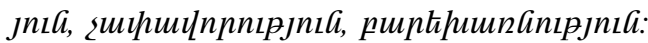

Though the English synonyms and related words for modesty (reserve, timidity, shyness, coyness, restraint, diffidence, bashfulness, virginity, constraint, backwardness, innocence, demureness, down-to-earthiness, humbleness, lowliness, meekness, humility, unpretentiousness, low-profile, self-deprecation, virtue, goodness, purity, decency, respectability, integrity, propriety, honour, shame, embarrassment, guilt, inhibition, chagrin, discomfort, cringe, ignominy, mortification, etc.) supersede their Armenian counter-

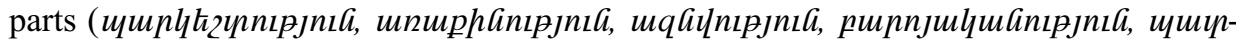

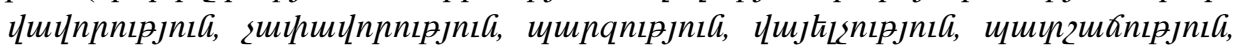

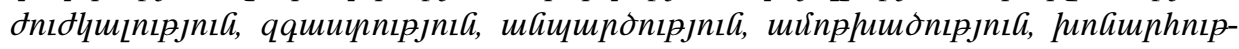

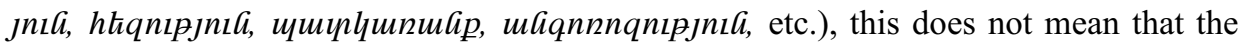
concept is of less importance for Armenians.

The British and Americans associate modesty with external human behaviour, and modesty is mainly associated with moderation in clothes and behaviour highlighted as a typical feature of the concept of women's lack of desire to feel sexually attractive. The perception of modesty is more leisurely and it can be subordinated to factors that are more important for a person from a Western background. The individualism and self-reliance ethic characteristic to British and American cultural identity are reflected in the definitions and perception of the concept modesty. In British English modesty is mainly defined as "the quality of not talking about or not trying to make people notice your abilities and achievements", in American English it is the quality of "correct or socially acceptable behaviour and clothes". What is called Western culture expects that intimate body parts are covered in public places at all times. Thus British and American cultural identity suggests that modesty should include: "avoiding attracting attention, by behaving the same way as everybody else, or as society expects; using clothing that generally follows the same norm, avoiding boasting with one's own accomplishments". In American English modesty is mainly opposed to wearing gorgeous clothes and too few clothes, and aims at prevention of desire, disgust, shame, or disapproval (Laver 1969:79-114). Modesty is a feeling or a behavior that is motivated by shame, in that it essentially bears upon the sexualized body... (Rubinstein 1995). For the British and Americans modesty does exist mainly as a social phenomenon: definitions of modesty that refer to perceptible propriety in dress, conduct, and behavior consistently come first. They 
associate modesty with closed clothing and etiquette, and see modesty as a regulative ideal behavior, and this quality is certainly positive, but in reality hinders the achievement of success and prosperity as Western culture exhorts people to cultivate ever higher self-esteem. American world view is based on principles of independence, on social attitudes to selfserving, catchy self-assessment and self-evaluation. Action, efficacy, persistence and achievement are emphasized and expected: "Just do it", "If there is a will there is a way", etc.

Most Asian nations that traditionally place a higher value on interpersonal relations see modesty and its significance diametrically opposed. In Armenia modesty is venerated and displays a variation in "value" conceptualization. It is centrally defined by "intrapsychic attributes" (Bond, Kwan \& Li 2000), that is, a person's virtue, humbleness, purity, timidity are of utmost importance. A modest person does not take credit, is humble, meek, free from conceit, lowly, thoughtful, not big-headed, plain/not flashy, unpretentious. Armenian modesty, bordering with timidity, suggests that modesty is more necessary for women than for men. A vast number of related words to modesty show humbleness, honesty, and/or bashfulness, and not moderation. Armenian "modesty" is "fixed" in the heart, the soul of the individual, so it finds expression in the appearance both in verbal and non-verbal behavior (the image

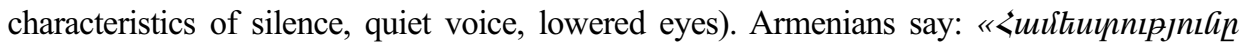

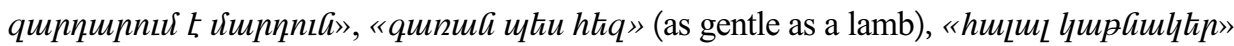

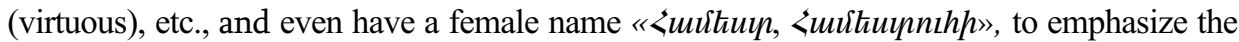
significance of this virtue. The English language doesn't possess proverbs in which modesty is "respected" so much. In Armenian it displays significant capabilities of word-formation:

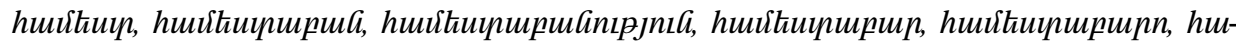

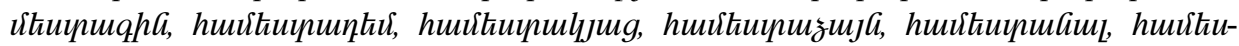

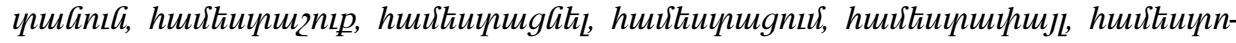

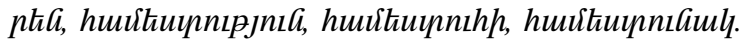

The British National Corpus (BYU-BNC), the Corpus of Contemporary American English (COCA), and Eastern Armenian National Corpus (EANC) provide exact statistics of the usage of the word modesty in various periods and genres of the English and Armenian languages The statistics is shown in the tables below and is evident how the word modesty/huufluupnıpjnıl has increased or decreased in frequency.

Modesty- BYU-BNC (BRITISH NATIONAL CORPUS (1980-1993)

\begin{tabular}{|c|c|c|c|c|c|}
\hline Period & Fiction & Non-Fiction & Magazines/Newspapers & Spoken & Total \\
\hline $\mathbf{1 9 8 0 - 1 9 9 3}$ & 63 & 152 & 51 & 8 & 274 \\
\hline Total & 63 & 152 & 51 & 8 & 274 \\
\hline
\end{tabular}

Modesty - COCA (CORPUS OF CONTEMPORARY AMERICAN ENGLISH) (1990-2012)

\begin{tabular}{|c|c|c|c|c|c|}
\hline Period & Fiction & Non-Fiction & Magazines/Newspapers & Spoken & Total \\
\hline$\underline{\mathbf{1 9 9 0 - 1 9 9 9}}$ & 0 & 0 & 0 & 63 & 63 \\
\hline $\mathbf{2 0 0 0 - 2 0 1 2}$ & 0 & 0 & 0 & 44 & 44 \\
\hline Total & 0 & 0 & 0 & 107 & 107 \\
\hline
\end{tabular}


zuútuunntpjnıG - Unluml /EANC/ (1900-2009)

\begin{tabular}{|c|c|c|c|c|c|}
\hline Period & Fiction & Non-Fiction & Magazines/Newspapers & Spoken & Total \\
\hline XX & 59 & 12 & 15 & 1 & 87 \\
\hline XXI & 38 & 2 & 36 & 9 & 85 \\
\hline Total & 106 & 15 & 51 & 10 & 182 \\
\hline
\end{tabular}

When comparing the data of the $20^{\text {th }}$ century, we can see that the word modesty was most frequent in British English: 274 usages from one million tokens (though the data are only for 13 years' period), the COCA gives only 63 tokens per one million usages and 87 tokens in EANC. In the 21 st century the frequency of usage of the word modesty decreased both in EANC (85) and in COCA (44). It could be concluded that modesty is not appreciated so much as it used to, and other values predominate in the linguo-cultures under study.

In sum, the comparative study of the concept modesty makes explicit differences and dissimilarities between different nations' approaches to ethical values, rooted in the histories, beliefs, norms and values of the nations. Thus, for Armenians modesty is a virtue and dignity, for the British it correlates with moderation, and for Americans as a typical feature of this concept stands out women's lack of sexual desire to appear attractive and to draw attention, therefore the concept modesty mainly includes external components: demeanor, dress, speech, according to generally accepted standards of etiquette.

Understanding of the concept modesty in the British, American and Armenian consciousness is in polar opposites due to the imperatives of the individualistic culture of the British and Americans and collectivist culture among Armenians (Hofstede 1997). The systems of values, moral and ethical standards and regulators of life that exist in Britain, America and Armenia, introduce and fix certain patterns and behaviours, and shape identities. And when understanding cultural identity as a multi-faceted construct, it is important to note that in communication the choice of portraying a specific facet of one's identity will be context specific and negotiated between the participants of the exchange.

\section{Notes:}

1. Enlightenment theorists maintained such physical rationale and added a political resonance to the modest woman. According to Jean-Jacques Rousseau, modesty was a necessary virtue in women because of their physical and sexual weaknesses. Standards of public honour, like fashions of dress, have changed dramatically over time. Standards of female modesty have undergone countless redefinitions over the years, in response to cultural, political, and economic factors (Laver 1969).

2. The stems of «huutiuun» are «huư and «tü» and this means: "both others and I" that is, not separating oneself from others.

3. While speaking about American linguo-culture, we take it as one entity considering the definitions of the word modesty in dictionaries, though we admit that US is a "melting pot"" and a mix of different ethnic and cultural values and beliefs. 


\section{References:}

1. Adler, P. (2002) Beyond Cultural Identity: Reflections on Multiculturalism. / Ed. by R. Brislin. Culture Learning, East-West Center Press.

2. Bond, M. H.; Kwan, V. S. Y.; \& Li, C. (2000) Decomposing a Sense of Superiority: The Differential Social Impact of Self-Regard and Regard for Others. // Journal of Research in Personality, 34.

3. Bray, Z. (2004) Living Boundaries: Identity and Frontiers in the Basque Country. Brussels: PIE Peter Lang.

4. Hofstede, G.H. (1997) Cultures and Organizations: Software of the Mind. The Netherlands: University of Limburg at Maastricht.

5. Laver, J. (1969) Modesty in Dress. Boston: Houghton Mifflin.

6. Rubinstein, R.P. (1995) Dress Codes: Meanings and Messages in American Culture. Boulder: Westview Press.

7. Sysoyev, P. V. (2001b) Language and Culture: Looking for a New Dimension in Teaching L2 Culture. // Foreign Languages at School, Journal, 4.

8. Acharyan, H. (1926) Hayeren armatakan bararan. Yerevan: Yerevani petakan hamalsarani hratakchutyun.

9. (1976) Ardi hayereni bacatrakan bararan. Vol. 1. Yerevan: Hayastan.

10. (2011) Cambridge Academic Content Dictionary. Cambridge: Cambridge University Press.

11. (1967) Hayots lezvi homanishneri bararan. Yerevan: NAS, Gitutyun.

12. (1974) Zhamanakakits hayots lezvi bacatrakan bararan. Yerevan: NAS, Gitutyun. Vol. 3.

13. $<$ http://www.mediate.com/articles/adler3.cfm\#bio $>$

14. $<$ http://www.harmonia.am/articleshnqtpuiduluuf punupuid22.html\#.UaNzFLWmgii >

15. <http://www.answers.com/topic/modesty\#ixzz2UVdOpsMg>

16. Gale Dictionary of Psychoanalysis:

$<$ http://www.answers.com/topic/modesty\#ixzz2UVYZ6FW>

17. $<$ http://www.macmillandictionary.com/thesaurus-category/british>

18. <http://www.merriam-webster.com/dictionary/modesty $>$

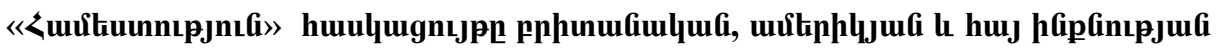 huưuutipuunnư}

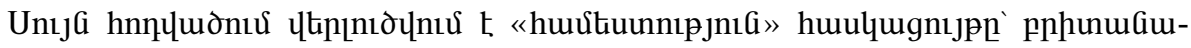

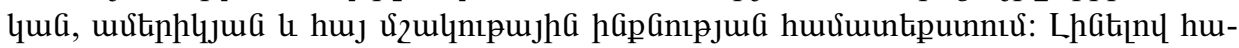

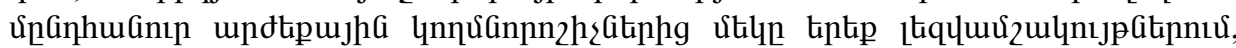

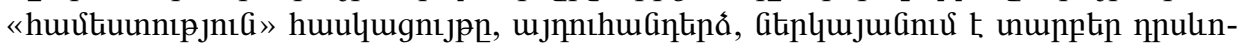

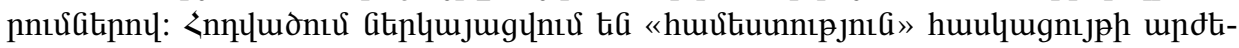

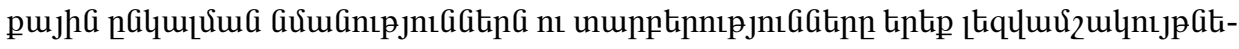
nnư: 